\title{
Prolonged survival time with surgical therapy in different types of thymoma: an analysis based on Surveillance Epidemiology and End Results Database
}

\author{
Jinsong Li, Quan Liu, Zhikun Zheng, Shoukang Li \\ Department of Thoracic Surgery, Union Hospital, Tongji Medical College, Huazhong University of Science and Technology, Wuhan, China \\ Contributions: (I) Conception and design: All authors; (II) Administrative support: J Li; (III) Provision of study materials or patients: S Li; (IV) \\ Collection and assembly of data: Q Liu, S Li; (V) Data analysis and interpretation: Z Zheng, S Li; (VI) Manuscript writing: All authors; (VII) Final \\ approval of manuscript: All authors. \\ Correspondence to: Shoukang Li, MD. Department of Thoracic Surgery, Union Hospital, Tongji Medical College, Huazhong University of Science \\ and Technology, Wuhan 430022, China. Email: shoukangli@hust.edu.cn.
}

\begin{abstract}
Background: Thymoma is the most common tumor within the anterior mediastinum though it is still a rare tumor disease. Surgery is considered to be one of the most important treatment methods for it, while radiotherapy and platinum-based chemotherapy are also in use. Based on the Surveillance, Epidemiology and End Results (SEER) database, we conducted our research and determined the value of operation in the treatment of thymoma.
\end{abstract}

Methods: In total, 1,587 patients with thymoma were selected out from the database. We grouped them according to type and stage of thymoma. We used cox-regression analysis to selected meaningful factors. Kaplan-Meier method was used for survival analysis.

Results: The mean survival times of patients with type A, B, C thymoma were 130.79, 123.81, 77.18 months orderly. Among all 1,587 patients, the mean survival time of those treated with surgery was 124.92 months, while it was 65.03 months for those without surgery treatment $(\mathrm{P}<0.05)$. Within each group of patients with the same kind of and same stage thymoma, who got surgical treatment had a longer survival period $(\mathrm{P}<0.05)$.

Conclusions: Type c thymoma had the worst prognosis. Patients who received surgical treatment had longer survival time. And it didn't matter what type or what stage of thymoma.

Keywords: Thymoma; surgery treatment; survival time; Surveillance, Epidemiology and End Results database (SEER database)

Submitted Feb 10, 2020. Accepted for publication Sep 03, 2020.

doi: 10.21037/tcr-20-951

View this article at: http://dx.doi.org/10.21037/tcr-20-951

\section{Introduction}

Thymoma is an uncommon disease, which is characterized by remarkable morphological heterogeneity and unique biological behavior. A study by the United States National Cancer Institute (NCI) has shown that the incidence of thymoma in the United States is 0.15 cases per 100,000 persons $(1,2)$. However, thymoma is the most common tumor disease in the area of anterior mediastinum. Therefore, it is important to study the effective treatment and prognostic factors of thymoma.

World Health Organization (WHO) in 2015 reclassified thymomas based on morphology and ratio of lymphocytes to epithelial cells. According to it, there were 6 categories of thymoma, A, AB, and B1 are the low-risk kinds, and B2 and $\mathrm{B} 3$ are the high-risk kinds. The sixth category is the thymic carcinoma (previously classified as type $\mathrm{C}$, and we used $\mathrm{C}$ to represent it) (3-6).

Complete surgical resection (R0) is the standard 
Table 1 The characteristics of the patients

\begin{tabular}{lcccc}
\hline Characteristics & $\mathrm{A}(\mathrm{A}, \mathrm{AB}, \mathrm{n}=430)$ & $\mathrm{B}(\mathrm{B} 1, \mathrm{~B} 2, \mathrm{~B} 3, \mathrm{n}=762)$ & $\mathrm{C}($ carcinoma, $\mathrm{n}=395)$ & Total $(\mathrm{n}=1,587)$ \\
\hline Race (Black/White/other) & $50 / 307 / 73$ & $123 / 510 / 129$ & $52 / 284 / 59$ & $225 / 1,101 / 261$ \\
Sex (male/female) & $213 / 217$ & $379 / 383$ & $249 / 146$ & $841 / 746$ \\
Surgery (done/no) & $384 / 46$ & $676 / 86$ & $228 / 167$ & $1,288 / 299$ \\
Age (rank) & $5.74 \pm 1.32$ & $5.07 \pm 1.47$ & $5.53 \pm 1.42$ & $5.37 \pm 1.44$ \\
Tumor size (mm) & $62[45-90]$ & $66.5[50-90]$ & $69[49-90]$ & $66[48-90]$ \\
\hline
\end{tabular}

therapeutic approach for almost all thymoma. However, for advanced and unresectable thymoma, a multimodality treatment regime is recommended (7-10). It can also be used as a supplement after surgery.

The Surveillance, Epidemiology, and End Results (SEER) Program provides information on cancer statistics of the United States in an effort to reduce the cancer burden among the U.S. and the whole world population. Based on it, we did retrospective research to find out the favorable prognostic factors of thymoma and look forward to providing advice on the treatment of the disease.

We present the following article in accordance with the STROBE reporting checklist (available at http://dx.doi. org/10.21037/tcr-20-951).

\section{Methods}

\section{Database}

We collected the data from SEER Nov. 2017 submission, which including the cancer data from 1973-2015 of the United States.

\section{Patients information}

The following characteristics of those patients were analysed in our study: sex (male/female), age (every ten years was put in the same age stage: stage 1 , aged 10-19; stage 2 , aged $20-29 \ldots$ stage 7 , aged $70-79$; stage 8 , aged $80+$ ), race (white/black/other), tumor type (histologic type ICD-O-3), ending (SEER cause-specific death classification, dead attributable to thymoma/alive or dead of other cause), time (survival months), size (CS tumor size 2004+, mm), surgery (performed/not), stage (derived SS1977 2004+; L, localized, I/R, regional, II to III/D, distant, IV).

Patients with incomplete information above were excluded. Eventually, a total of 1,587 patients was included in this study.

\section{Statistical analysis}

All statistical analyses were performed by using SPSS 17.0 (SPSS Inc., Chicago IL, USA). Data were tested for normality and homogeneity of variance.

A cox-regression was used to screen for significant prognostic factors among all patients and patients in different groups. A Kaplan-Meier method with log-rank test was used for survival analysis. $\mathrm{P}$ value smaller than 0.05 was considered statistically significant.

The study was conducted in accordance with the Declaration of Helsinki (as revised in 2013).

\section{Results}

\section{Patients characteristics}

Of the 1,587 patients, 841 were men and 746 were women. There were 225 black patients and 1,101 white patients. The rest 261 patients were in other races. A total of 1,288 patients ever underwent surgery, and the average diameter of tumors in all patients was $66 \mathrm{~mm}$. The information of sex, race, age, surgical treatment state and tumor size of patients with different kinds of thymoma is shown in Table 1 .

\section{The results of cox-regression analysis for all patients and patients with different kinds of thymoma}

The survival times of patients with type A (including A and $\mathrm{AB}), \mathrm{B}$ (including B1, B2 and B3), C thymoma were totally different. However, in patients with different subtypes thymoma (type $\mathrm{A}$ and $\mathrm{AB} ; \mathrm{B} 1, \mathrm{~B} 2$ and $\mathrm{B} 3$ ), there was no significant difference in survival time.

Surgical treatment is an independent factor in favor of prognosis. Patients who received surgical treatment had longer survival, whether they were type A thymoma, type B thymoma or type C thymoma. Stage of disease is another independent factor in favor of prognosis except in A thymoma (Table 2). 
Table 2 The prognostic factors of thymoma

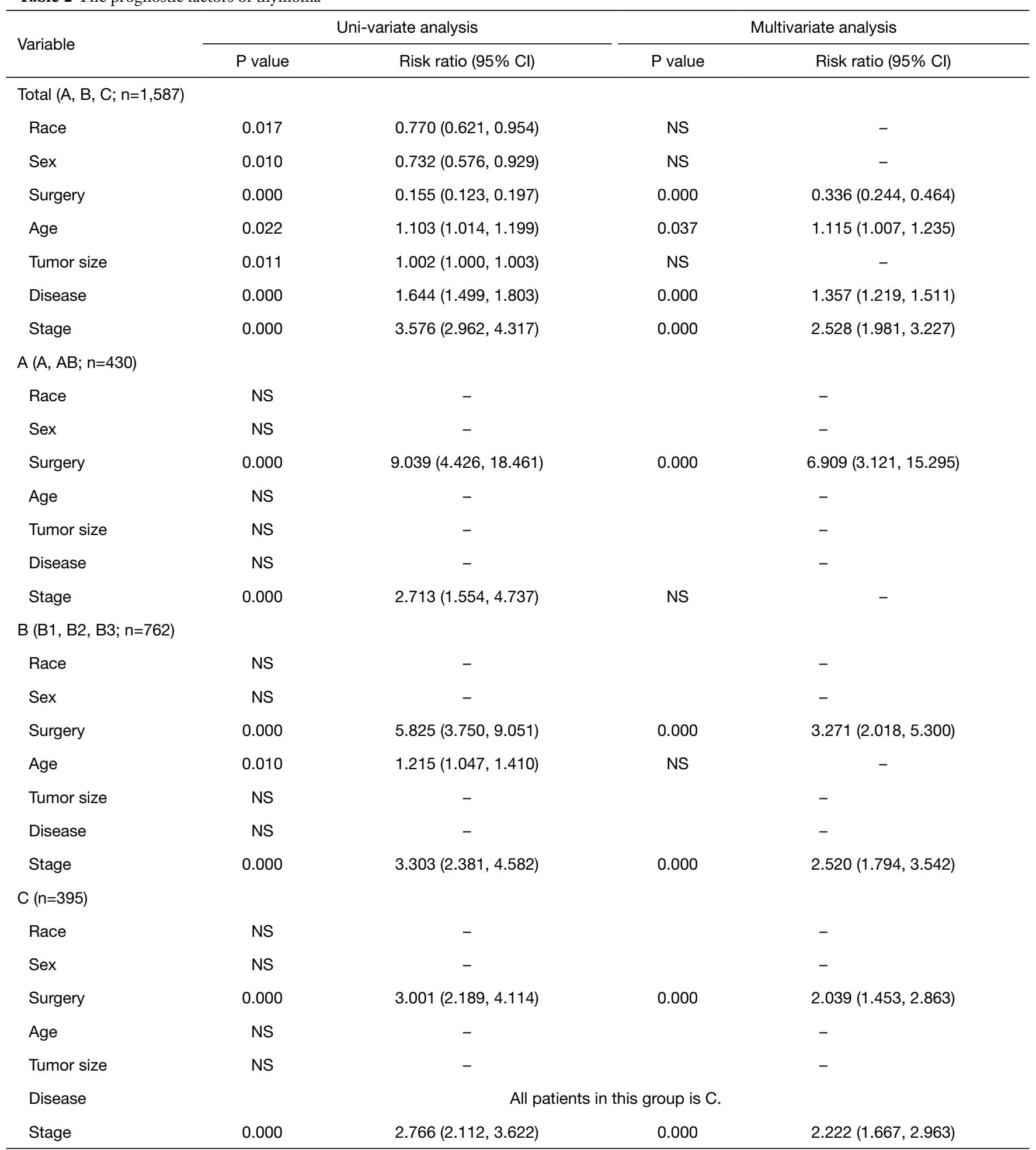

NS, not significant. 


\section{The survival time of patients with different kinds of thymoma}

The mean survival times of type A, B, C thymoma were $130.79,123.81,77.18$ months. The results are shown in Table 3 and Figure 1.

\section{The survival time of patients with/without surgery treatment}

All patients were categorized as Masaoka-Koga stage groupings of I and IIA (localized, L), IIB ('regional', R), III and IV ('distant', D). The staging of patients with different types of thymoma was shown in Table 4.

According to the stage groupings and types of the disease, we divided all patients into 9 groups and found out that patients who had ever accepted surgery had a longer survival period in all groups (Table 5 and Figure 2).

\section{Discussion}

Thymomas are rare neoplasms accounting for only $0.2 \%$ to $1.5 \%$ of all malignancies. Despite the rarity, however, they comprise about $20 \%$ of all mediastinal masses and account for up to $50 \%$ of anterior mediastinal masses $(11,12)$.

Thymomas are thymic epithelial tumors (TETs). The majority of them have non-malignant-appearing thymic epithelial cells mixed with variable proportions of lymphocytes. TETs have been a subject of much

Table 3 The survival time of patients with different kinds of thymoma

\begin{tabular}{lcc}
\hline Type & Survival time (months) & P value \\
\hline A & $130.79(126.65,134.93)$ & 0.000 \\
B & $123.81(120.30,127.32)$ & \\
C & $77.18(70.32,84.04)$ & \\
\hline
\end{tabular}

controversy over years because of the difficulties in predicting prognosis. Due to the complexity in classification of these tumours, many histological methods have been described in the literature for thymic neoplasms (13-17). In the newest $\mathrm{WHO}$ system, there are six different types of thymic tumours, A, AB, B1, B2, B3 and thymic carcinoma (we used $\mathrm{C}$ to stand for it in our research), based on the rate of non-malignant-appearing thymic epithelial cells and proportions of lymphocytes $(3,18-20)$.

The most widely accepted staging system of thymic tumors was proposed by Masaoka and it was afterwards modified by Koga in 1994. In Masaoka-Koga staging system, stage I means grossly and microscopically completely encapsulated tumor; tumors with invasion into surrounding tissues but not breaking through mediastinal pleura or pericardium belong to stage II; stage III includes tumors with macroscopic invasion into neighboring organ; stage IV means tumors with metastasis (13).

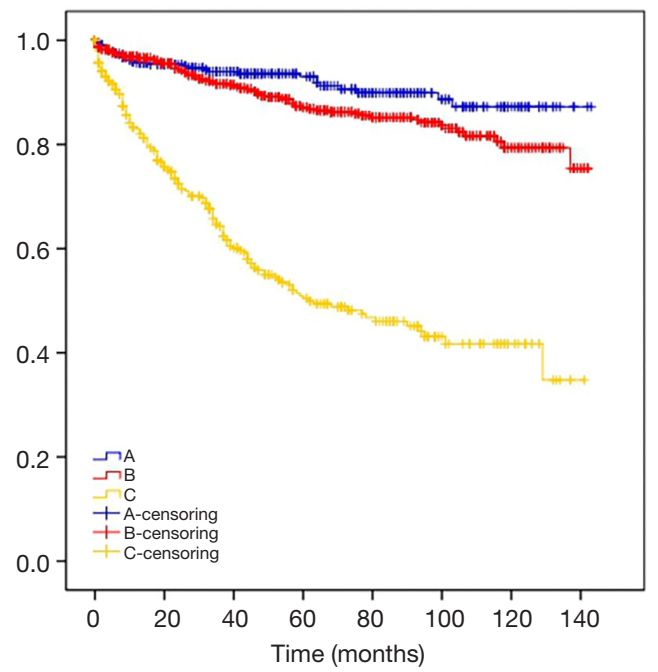

Figure 1 The survival time of patients with type A, B and C thymoma.

Table 4 The staging of patients with different types of thymoma

\begin{tabular}{lccc}
\hline Type & L (with/without surgery) & $\mathrm{R}$ & $\mathrm{D}$ \\
\hline $\mathrm{A}$ & $181(177 / 4)$ & $207(185 / 22)$ & $42(22 / 20)$ \\
$\mathrm{B}$ & $236(220 / 16)$ & $371(349 / 22)$ & $155(107 / 48)$ \\
$\mathrm{C}$ & $52(45 / 7)$ & $183(133 / 50)$ & $160(50 / 110)$ \\
Total & 469 & 761 & 357 \\
\hline
\end{tabular}

L: localized, I and IIA; R: regional, IIB; D: distant, III and IV. 
Table 5 The survival time of different kinds/stages thymoma patients with/without surgical treatment

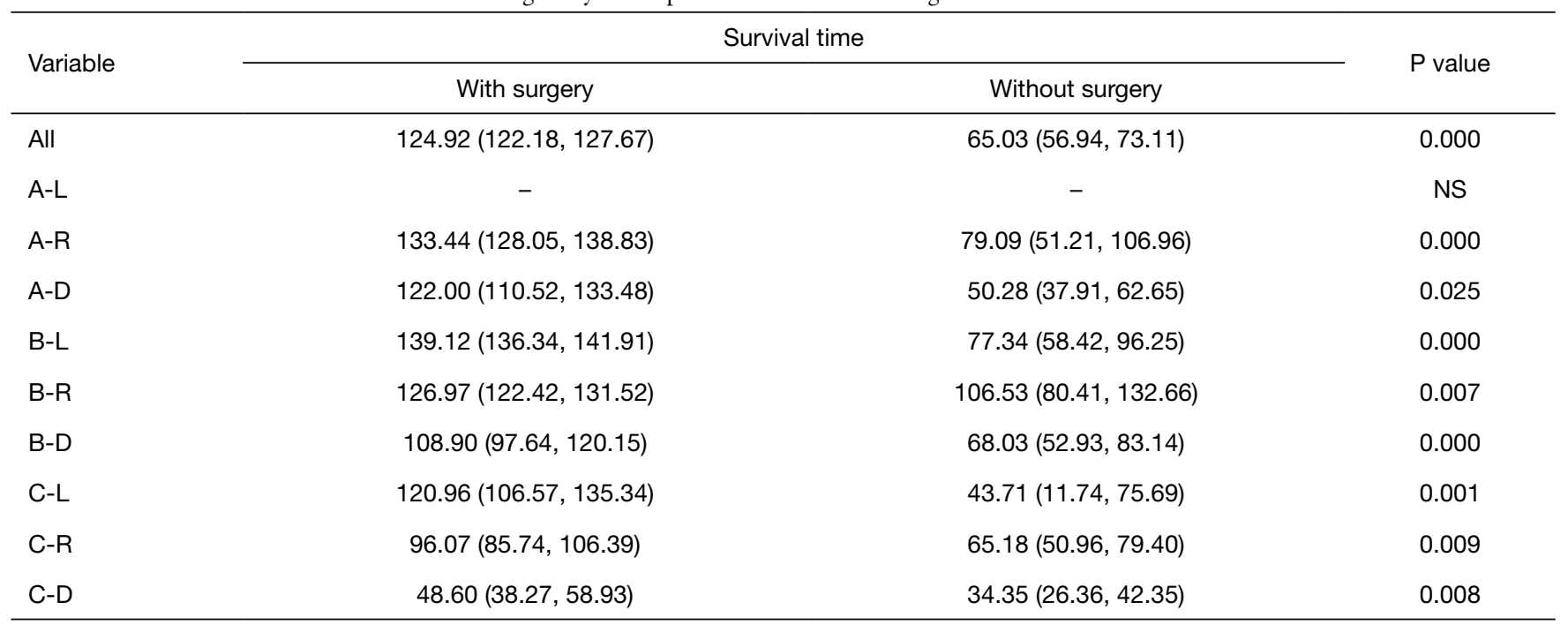

L: localized, I and IIA; R: regional, IIB; D: distant, III and IV.
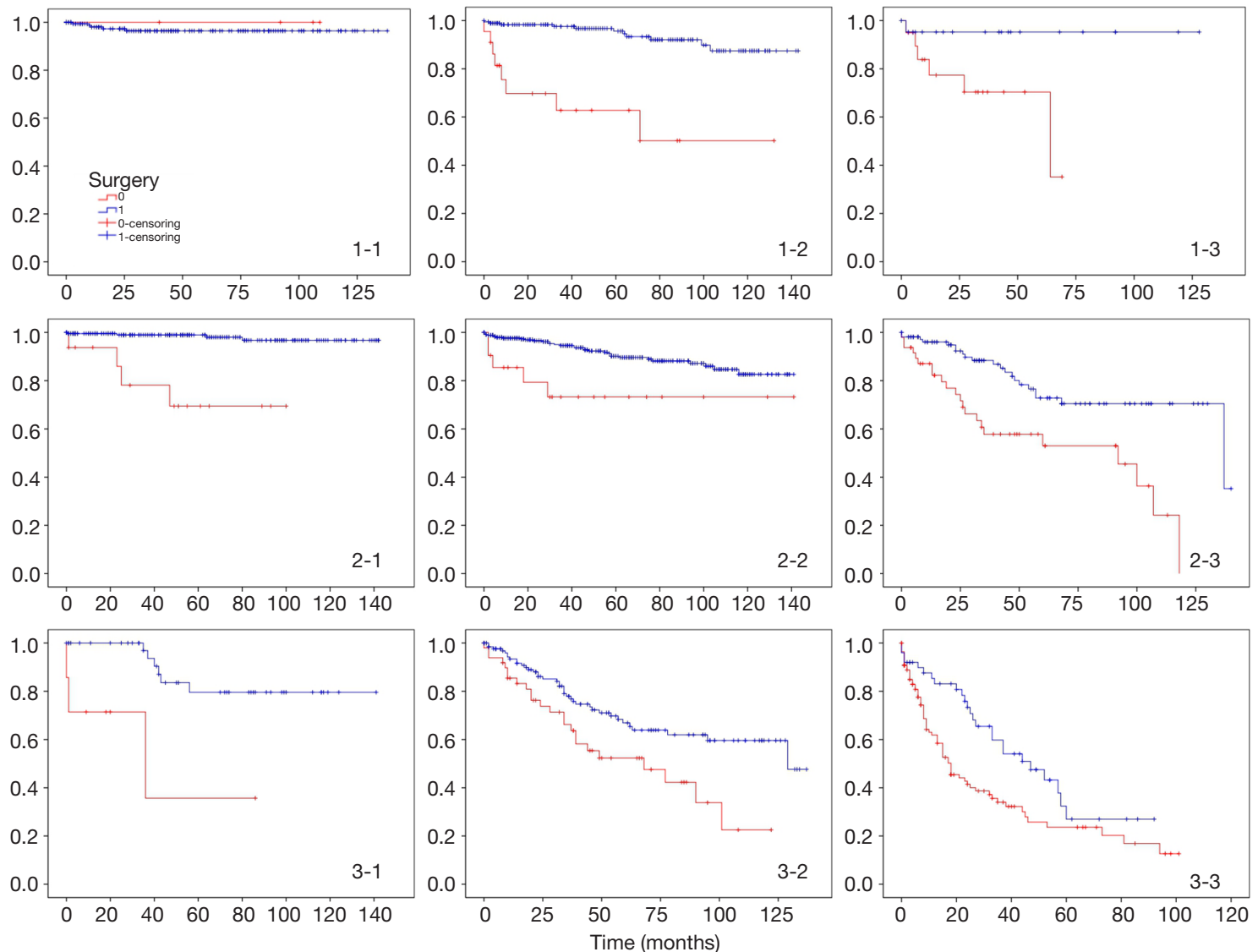

Figure 2 The survival time of different kinds/stages thymoma patients with/without surgical treatment. Surgery 0: without surgical treatment; surgery 1: with surgical treatment. 1-1: localized-stage type A thymoma; 1-2: regional-stage type A thymoma; 1-3: distantstage type A thymoma; 2-1: localized-stage type B thymoma; 2-2: regional-stage type B thymoma; 2-3: distant-stage type B thymoma; 3-1: localized-stage type $\mathrm{C}$ thymoma; 3-2: regional-stage $\mathrm{C}$ thymoma; 3-3: distant-stage $\mathrm{C}$ thymoma. 
Surgery is the mainstay of treatment for thymomas, especially the R0 resection. Radiotherapy plays a role in selected cases (stage III patients or R1-2 residual) and platinum-based chemotherapy remains the standard of care for patients with advanced disease. A multimodality approach would be advisable when surgery is not recommended (21).

We conducted our research based on SEER, which provides information on cancer statistics of the U.S.

In our research, we found the following facts. Firstly, patients with different types of thymic tumors had different average survival periods. Type A had the longest survival time while the carcinoma had the shortest. However, for the sub-type, like B1, B2 and B3, the survival times were not significantly different. The prognosis of thymoma cannot be well distinguished by the present classification of thymoma subtypes.

Secondly, surgical management was an independent beneficial prognostic factor for thymoma, whatever the disease's stage or type. However, for the patients with type A thymoma at stage I, only 4 of them didn't get surgical treatment while the other 177 patients got. The sample composition of this group was not appropriate, so the result was not reliable. The results of other groups showed that patients with thymoma could always get benefits from surgery, no matter what kind or stage of thymoma.

The study still had defects. The reasons for patients not receiving surgical treatment were not recorded, and the impact of this confounding factor on outcomes could not be ignored. However, the design of a prospective study for the selection of patients in surgical and non-surgical subgroups will also be constrained by medical ethics. In addition, the population of this study was small, and it was even smaller after grouping according to different types and stages. A study with a larger population could be more persuasive.

Nevertheless, our work stated that surgery remained the best treatment for all thymic tumors, regardless of stage and classification.

\section{Conclusions}

Surgical management was an independent beneficial prognostic factor for thymoma, whatever the disease's stage or type. All patients with thymic tumors should seek surgical treatment as soon as possible.

\section{Acknowledgments}

We are grateful to the Department of Thoracic Surgery,
Union Hospital, Tongji Medical College, Huazhong University of Science and Technology, Wuhan, China.

Funding: None.

\section{Footnote}

Reporting Checklist: The authors have completed the STROBE reporting checklist. Available at http://dx.doi. org/10.21037/tcr-20-951

Conflicts of Interest: All authors have completed the ICMJE uniform disclosure form (available at http://dx.doi. org/10.21037/tcr-20-951). The authors have no conflicts of interest to declare.

Ethical Statement: The authors are accountable for all aspects of the work in ensuring that questions related to the accuracy or integrity of any part of the work are appropriately investigated and resolved. The study was conducted in accordance with the Declaration of Helsinki (as revised in 2013).

Open Access Statement: This is an Open Access article distributed in accordance with the Creative Commons Attribution-NonCommercial-NoDerivs 4.0 International License (CC BY-NC-ND 4.0), which permits the noncommercial replication and distribution of the article with the strict proviso that no changes or edits are made and the original work is properly cited (including links to both the formal publication through the relevant DOI and the license). See: https://creativecommons.org/licenses/by-nc-nd/4.0/.

\section{References}

1. Bian D, Zhou F, Yang W, et al. Thymoma size significantly affects the survival, metastasis and effectiveness of adjuvant therapies: a population based study. Oncotarget 2018;9:12273-83.

2. National Comprehensive Cancer Network. NCCN Clinical Practice Guidelines in Oncology. Thymomas and Thymic Carcinomas. Version 2.20122012.

3. Marx A, Chan JK, Coindre JM, et al. The 2015 World Health Organization Classification of Tumors of the Thymus: Continuity and Changes. J Thorac Oncol 2015;10:1383-95.

4. Travis WD, Brambilla E, Müller-Hermelink HK, et al. Pathology and Genetics of Tumours of the Lung, Pleura, Thymus and Heart. IARC Press, 2004. 
5. Rosai J, Sobin L. Histological Typing of Tumours of the Thymus. 1999

6. Travis WD, Brambilla E, Burke AP, et al. WHO classification of tumours of the lung, pleura, thymus and heart. IARC Press, 2015.

7. Marchevsky A, Marx A, Strobel P, et al. Policies and reporting guide-lines for small biopsy specimens of mediastinal masses. J orac Oncol 2011;6:S1724-9.

8. Marchevsky AM, Hammond EH, Moran C, et al. Protocol for the examination of specimens from patients with thymic epithelial tumors located in any area of the mediastinum. Arch Pathol Lab Med 2003;127:1298-303.

9. Weydert JA, De Young B, Leslie K. Recommendations for the reporting of surgically resected thymic epithelial tumors. Am J Clin Pathol 2009;132:10-5.

10. Moran CA, Suster S. On the histologic heterogeneity of thymic epithelial neoplasms. Impact of sampling in subtyping and classification of thymomas. Am J Clin Pathol 2000;114:760-6.

11. Mullen B, Richardson JD. Primary anterior mediastinal tumors in children and adults. Ann Thorac Surg 1986;42:338-45.

12. Strollo DC, Rosado de Christenson ML, Jett JR. Primary mediastinal tumors. Part 1: tumors of the anterior mediastinum. Chest 1997;112:511-22.

13. Scorsetti M, Leo F, Trama A, et al. Thymoma and thymic

Cite this article as: Li J, Liu Q, Zheng Z, Li S. Prolonged survival time with surgical therapy in different types of thymoma: an analysis based on Surveillance Epidemiology and End Results Database. Transl Cancer Res 2020;9(10):5893-5899. doi: $10.21037 /$ tcr-20-951 carcinomas. Crit Rev Oncol/Hematol 2016;99:332-50.

14. Okumura M, Ohta M, Miyoshi S, et al. Oncological significance of WHO histological thymoma classification. A clinical study based on 286 patients. Jpn J Thorac Cardiovasc Surg 2002;50:189-94.

15. Kornstein MJ. Thymoma classification my opinion. Am J Clin Pathol 1999;112:304-7.

16. Marx A, Muller-Hermelink HK. Thymoma and thymic carcinoma. Am J Surg Pathol 1999;23:739-42.

17. Harris NL, Muller-Hermelink HK. Thymoma classification. A siren's song of simplicity. Am J Clin Pathol 1999;112:299-303.

18. Travis WD, Brambilla E, Nicholson AG, et al. The 2015 World Health Organization Classification of Lung Tumors: Impact of Genetic, Clinical and Radiologic Advances Since the 2004 Classification. J Thorac Oncol 2015;10:1243-60.

19. Rosai J. Histological typing of tumors of the thymus. World Health Organization international histological classification of tumors.2nd edn. Berlin: Springer-Verlag, 1999.

20. Suster S, Moran CA. Thymoma classification: current status and future trends. Am J Clin Pathol 2006;125:542-54.

21. Scorsetti M, Leo F, Trama A, et al. Thymoma and thymic carcinomas. Crit Rev Oncol Hematol 2016;99:332-50. 